\title{
Plum Pox in North America: Identification of Aphid Vectors and a Potential Role for Fruit in Virus Spread
}

\author{
Frederick Gildow, Vern Damsteegt, Andrew Stone, William Schneider, Douglas Luster, and Laurene Levy
}

First author: Department of Plant Pathology, Penn State University, University Park 16802; second, third, fourth, and fifth authors: U.S. Department of Agriculture (USDA)-Agricultural Research Service, Foreign Disease-Weed Science Research Unit, Fort Detrick, MD 21702; and sixth author: USDA-APHIS-CPHST, BARC-East, Beltsville, MD 20705.

Accepted for publication 13 April 2004.

\begin{abstract}
Gildow, F., Damsteegt, V., Stone, A., Schneider, W., Luster, D., and Levy, L. 2004. Plum pox in North America: Identification of aphid vectors and a potential role for fruit in virus spread. Phytopathology 94:868-874.

Thirteen aphid species were tested for their ability to transmit Pennsylvania isolates of Plum pox virus (PPV) collected in Columbia (PENN-3), Franklin (PENN-4), and York (PENN-7) Counties, PA. Four species, Aphis fabae, A. spiraecola, Brachycaudus persicae, and Myzus persicae, consistently transmitted PPV in preliminary transmission tests. Two species, Metopolophium dirhodum and Rhopalosiphum padi, were occasional inefficient vectors. Toxoptera citricida, from Florida, also was an effective vector but it does not occur in major stone-fruit-growing states.

Species not transmitting PPV in parallel tests included Acyrthosiphon pisum, Aphis glycines, Aulacorthum solani, Macrosiphum euphorbiae, Rhopalosiphum maidis, and Sitobion avenae. When given a 3-day probing access period simultaneously on PPV-infected peach seedlings and healthy peach seedlings, Myzus persicae, Aphis spiraecola, A. fabae, and B. persicae transmitted PPV to $63,31,38$, and $32 \%$ of the healthy peach seedlings, respectively. When given a similar probing period on PPV-infected peach fruit and healthy peach seedlings, the same aphid species transmitted PPV to 50, 35, 0, and $0 \%$ of seedlings, respectively. Results support the hypothesis of secondary PPV spread by indigenous aphids in Pennsylvania, and suggest that PPV-infected fruit has the potential to function as a virus source for long-distance dispersal.
\end{abstract}

Plum pox is one of the most devastating virus-induced diseases of stone fruit (Prunus spp.). The disease was first described in eastern Europe in the early 1900s as a disorder of plums referred to as "sharka", meaning pox in Bulgarian. Plum pox currently is found throughout western Europe and along the Mediterranean basin as far as Egypt $(16,18,26)$. In 1992, plum pox was detected in South America in stone fruit in Chile (23,25); and, in 1999, plum pox was first identified in North America in several peach and plum orchards in Adams County, PA $(6,14)$. A second North American focus of plum pox was detected in Ontario, Canada, in 2000.

The causal agent, Plum pox virus (PPV; genus Potyvirus; family Potyviridae), accumulates to relatively low titer and is unevenly distributed in host trees. In some host plant species, PPV induces mild foliar symptoms that may include veinal chlorosis, ringspots, and distortion on relatively few leaves per tree $(7,30)$. For these reasons, initial detection may be difficult and the virus accidentally can be spread long distances across natural barriers by infected nursery stock and budwood (22). Short-distance spread between trees and among orchards is accomplished by aphids transmitting PPV in a nonpersistent manner (8). Disease symptoms and effects on fruit production vary with host species, but chronic infection leads to tree decline and premature death. Currently, PPV is grouped into four recognized strains (PPV-D, PPV$\mathrm{M}$, PPV-C, and PPV-EA) based on biological, serological, and molecular characteristics $(2-4,10,21,31)$. Although symptoms are similar among strain types, they can be differentiated by serological tests of capsid proteins (3), differences in nucleotide sequence

Corresponding author: F. Gildow; E-mail address: feg2@psu.edu

Publication no. P-2004-0617-01R

This article is in the public domain and not copyrightable. It may be freely reprinted with customary crediting of the source. The American Phytopathological Society, 2004
(4), differences in host range (5), and differences in vector efficiency. At this time, all PPV isolates characterized in North and South America are related to PPV-D-like strains $(6,23)$.

The predominant aphid species responsible for transmitting PPV within a given geographical area differs from region to region throughout Europe $(9,13,32)$. In addition, distinct populations or biotypes of aphid species differ genetically in their ability to transmit PPV and other potyviruses $(13,17)$. Likewise, distinct isolates or strains of PPV differ genetically, influencing aphid transmission efficiency. In France, the typical PPV-D isolates are not spread effectively by aphids to peach. However, some recently discovered PPV-D isolates are unique in being readily spread to peach (5). Ability of an aphid species to feed and survive or colonize on Prunus spp. is not a prerequisite for efficient PPV transmission. Of 40 aphid species tested as PPV vectors in France, 14 species were demonstrated to be genetically competent to consistently transmit PPV (13). However, only four of these species normally feed and survive on stone fruit (Prunus spp.). Most PPV vectors are migrant aphid species originating on adjacent crops or on ground cover and weeds. These migrants first acquire the virus upon entering the orchard while initiating a test probe on an infected tree. The viruliferous aphid then loses the infectious virus upon its next probe into a leaf of the same or an adjacent plant. Although PPV is acquired in seconds or minutes from the leaf epidermis, it remains infectious in the aphid for only a short time (nonpersistent transmission). For this reason, initial PPV spread often is localized within 10 to $50 \mathrm{~m}$ of infected source trees (19). Because aphids are carried primarily on wind currents, the landscape topography, wind direction, wind speed, and distance between hosts strongly influence PPV spread. Diseased trees often occur as a gradient downwind from the initially infected reservoir trees. Therefore, patterns of disease spread can give information on the likely mode of transmission, location of infected source plants, and estimations of rate of spread from time of introduction. Although transmission tests indicated that populations of 
Myzus persicae were the most efficient vectors of PPV in France (13) and Spain $(15,16)$, the number of aphids of a given species within the total aphid population may have a more significant influence on ability to transmit. In an orchard study on apricots in France (11), it was shown that approximately 141,000 aphids may land on a tree per season. Of these, 61,000 would be probable PPV vectors and, based on transmission tests of field-collected aphids, approximately 61 of these aphids could be expected to transmit PPV from a nearby source. Therefore, a relatively inefficient PPV vector species could be important if it made up a high proportion of the total aphid population.

Introduction of PPV to new areas previously protected by natural barriers or long distances from infected sources has most often been traced to importation of infected vegetative planting material. Current evidence does not support a major role for seed or pollen transmission in PPV epidemiology $(20,29)$. Until recently, fruit harvested from infected trees was thought to play no role in PPV spread. Because PPV was not known to be seed-transmitted to germinating seedlings and aphids were not believed to feed on or transmit PPV from fruit, fruit from PPV-infected areas has not been restricted in international trade and few precautions were considered necessary to safeguard against PPV movement by fruit. A report in 2000 (12), however, indicated that M. persicae probing on PPV-infected apricot and peach could transmit French isolates of PPV to peach seedlings under controlled laboratory conditions. These results suggested the possibility of a previously unknown avenue for PPV survival and movement.

Upon the discovery of PPV-infected peach and plum orchards in Adams County, PA in September 1999, a rapidly performed PPV survey program indicated a localized foci of infection. Based on this evidence, a quarantine and eradication program was immediately initiated in conjunction with intensive enzyme-linked immunosorbent assay (ELISA) and polymerase chain reaction (PCR) surveys by the Pennsylvania Department of Agriculture and U.S. Department of Agriculture (USDA)-Animal and Plant Health Inspection Service (APHIS). At the same time, biological studies were initiated by personnel at Pennsylvania State University and the USDA-Agricultural Research Service (ARS) Foreign Disease and Weed Science Research Unit at Ft. Detrick, MD, to characterize the PPV isolates occurring in the quarantined area, to identify potential vectors, and to test alternative natural and weed hosts. This information was considered essential for developing plum pox disease management strategies should eradication efforts not succeed, or to assist in controlling PPV outbreaks in the event of future reintroductions. The objectives of this project were to (i) collect and identify aphid species common to Pennsylvania stone fruit orchards, (ii) develop protocols for maintaining these aphids for long-term studies, (iii) identify those aphid species capable of transmitting several Pennsylvania isolates of PPV, and (iv) test for the ability of Pennsylvania aphids to acquire and transmit PPV from fruit collected from naturally infected trees. Independent verification of the potential role of infected fruit in PPV spread was important to gain evidence supporting management strategies associated with disposal of PPV-infected fruit; and to aid in future risk assessments associated with inspection and importation of fruit shipped from PPV-infected areas.

\section{MATERIALS AND METHODS}

Aphid clones. Most aphid species used in tests were collected in July 2001, at the Pennsylvania State University Fruit Research and Extension Center (FREC) in Biglerville, PA. Aphids were collected in a peach orchard from trees and associated herbaceous ground cover in and around the orchard with assistance from G. Krawczyk (FREC, Department of Entomology). No aphid species were observed colonizing peach at this time and aphids were assumed to represent migrants. Aphids were returned to the University Park campus and preliminary identifications were made to determine the species. Additional aphid species were obtained from other sources. Aphis glycines was collected from a soybean field at the Pennsylvania State University Larson Research Farm, Rock Springs, PA. Brachycaudus persicae was obtained from P. Shearer (Rutgers University). Toxoptera citricida was acquired from a Florida population maintained at the USDA-ARS Biocontainment Facility at Ft. Detrick, MD. Plant host range tests were performed to identify appropriate herbaceous hosts for continuous rearing of each aphid species in a controlled-environment rearing facility maintained at $20^{\circ} \mathrm{C}$ and $60 \%$ relative humidity with continuous light to inhibit development of sexual forms. Asexually reproducing clonal populations of each species were initiated using one apterous female adult per species. Plant species allowing optimal survival and growth of each aphid species were used to initiate healthy virus-free colonies every 3 weeks using 20 aphids per plant. Host plants and aphids were grown in screened box cages with a constant 24-h photoperiod under fluorescent lighting (Cool White Plus and GroLux; Osram Sylvania Lighting Prod., Versailles, KY).

Representative aphids of each clone were stored in $70 \%$ ethanol and sent to S. E. Halbert (Florida Department of Agriculture and Consumer Services, Gainesville) for species verification and recording of voucher specimens. Additional identifications were verified by M. Stoetzel (Systematic Entomology Lab., USDA, Beltsville, MD). Listed below are the aphid species according to the nomenclature of Blackman and Eastop (1) and the host plant on which each aphid species was reared: pea aphid, Acyrthosiphon pisum (Harris), on fava bean, Vicia faba L.; black bean aphid, Aphis fabae Scoploi, on V. faba; soybean aphid, A. glycines Matsumura, on soybean, Glycine $\max$ (L.) Merr.; spirea aphid, A. spiraecola Patch (=A. citricola van der Goot), on carrot, Daucus carota L.; foxglove aphid, Aulacorthum solani (Kaltenbach), on curly dock, Rumex crispus L.; black peach aphid, B. persicae (Passerini), on peach, Prunus persica Siebold \& Zuccarini cv. Nemaguard; potato aphid, Macrosiphum euphorbiae (Thomas) on green pepper, Capsicum annuum L.; rose-grain aphid, Metopolophium dirhodum (Walker) on barley, Hordeum vulgare L. cv. Barsoy; green peach aphid, Myzus persicae (Sulzer) on turnip, Brassica rapa L.; corn leaf aphid, Rhopalosiphum maidis (Fitch) on $H$. vulgare; bird cherry-oat aphid, $R$. padi (L.), on H. vulgare; English grain aphid, Sitobion avenae (F.), on H. vulgare; and T. citricida (Kirkaldy), on trifoliate orange, Poncirus trifoliata (L.).

PPV isolates. Three isolates of PPV, collected from three geographically distinct locations in Pennsylvania, were used in this study. Each isolate originally was obtained from an infected peach tree showing distinct PPV symptoms in leaves or fruit and testing positive for PPV by ELISA using the standard Durviz PPV kit (Agdia, Elkhart, IN). PPV isolate PENN-3 originally was recovered from an infected tree growing in Cumberland County, PA, in 2000; PENN-4 from infected peach fruit growing in Franklin County, PA, in 2001; and PENN-7 from peach fruit growing on an infected tree in York County, PA, in 2002. Following identification of PPV infection and recovery of infected buds or fruit for PPV isolation and characterization, all trees were destroyed as part of the eradication program. Infected buds and fruit were transported to the USDA biocontainment facility at Ft. Detrick, MD. Infected buds were grafted to Prunus persicae cv. Lovell or Nemaguard rootstocks for PPV isolate maintenance. Peach fruit were stored at $4^{\circ} \mathrm{C}$ until used for aphid transmission of infecting virus to peach seedlings.

PPV isolates were recovered from the originally infected tissues using $M$. persicae and transmission to 7-day-old Colmo pea (Pisum sativum cv. Colmo) or to 30-day-old peach seedlings (Prunus persica cv. Lovell). Obvious disease symptoms developed in peach between 30 and 60 days postinoculation. Original attempts to transmit PPV from peach to pea using aphids or mechanical inoculation were very inefficient and symptom production in pea required 20 to 30 days. However, once PPV was trans- 
mitted into pea and was inoculated sequentially from pea to pea, the virus adapted to pea and produced high virus titers and obvious severe mosaic symptoms within 10 days postinoculation. Following 10 serial transmissions in pea, the pea-adapted isolates of PPV were tested and found to retain their ability to be consistently transmitted with $50 \%$ efficiency from pea back to peach by $M$. persicae. Adaptation to pea did not negatively influence aphid transmissibility or ability to infect peach.

All PPV isolates and infected tissues were maintained in the USDA-ARS Foreign Disease and Weed Science Research Laboratory's BSL-3P biocontainment facility located at Ft. Detrick, Frederick, MD following USDA-APHIS permit no. 46471 guidelines for research on quarantined PPV-infected plant materials.

Transmission tests for vector competence. To initiate transmission tests, 3-week-old aphid colonies reared at the Pennsylvania State University facility were harvested by detaching the plants with associated aphids and transporting them to the Ft. Detrick facility in Frederick, MD in large plastic containers with tight-fitting lids. All transmission tests with PPV were conducted in the USDA-ARS BSL-3P greenhouse facility. Preliminary studies for genetic competency of different aphid species to transmit PPV were performed using Colmo pea as both the PPV acquisition source tissue and the inoculation bioassay plant. These tests are referred to as the pea-to-pea tests. Pea was selected for preliminary tests because rapid symptom development reduced time between experiments, and most aphid species probed more readily on pea compared with peach. In addition, the high virus titer detected in pea leaves, compared with peach, suggested increased opportunity for acquisition. To begin an experiment, aphids were collected from their respective host plants by shaking onto white paper and then transferred to empty plastic dishes and given a 1-h starvation period. The aphids then were transferred to a dish containing detached pea leaves and tendrils from 3- to 4-week-old PPV-infected peas. Aphids were allowed to settle and begin probing on the detached leaves for 15 to $30 \mathrm{~min}$, and then leaves or tendril tissue with attached probing aphids were placed in a small cage containing a single 7-day-old pea seedling approximately $2 \mathrm{~cm}$ in height. Aphids were free to move between the infected tissue and healthy pea seedling for $24 \mathrm{~h}$, then the seedlings were sprayed with Avid (Novartis Crop Protection, Inc., Greensboro, NC) and Malathion (Prentiss Inc., Sandersville, GA) insecticides to kill the aphids. Plants were maintained in a greenhouse for 30 days and observed for symptoms, then assayed by ELISA to verify infection.

To measure vector efficiency by single aphids, starved aphids were placed on PPV-infected pea leaf tissue and observed for probing using a stereo dissecting microscope. Individual aphids observed to probe on the leaf for 1 to 2 min then were removed using a small camel hair brush and placed singly on caged 7-dayold peas seedlings for a 24-h inoculation access period. Plants were sprayed with insecticide and observed for symptoms over a 3-week period, and then tested by ELISA.

Once the most effective vector species were identified, these species were tested for their ability to acquire and transmit PPV from peach to peach. To initiate a peach-to-peach test, aphids were collected and starved for 30 to $60 \mathrm{~min}$. Then, $\approx 500$ aphids were placed on a caged PPV-infected peach seedling 60 to 90 days postinoculation. All peach seedlings were tested by ELISA and PCR to verify PPV infection before use as source plants. The infected peach seedling with probing aphids was placed centrally in a $46-\mathrm{cm}^{2}$ plexiglass-screen box cage, and surrounded with five 4- to 6-week-old peach seedlings (cv. Lovell). Aphids were allowed to move freely between the infected and healthy plants over a 3-day inoculation access period. Plants were sprayed with insecticide, moved to the greenhouse, and observed for symptoms over a 30- to 60-day period and assayed by ELISA to verify infection. Infected test plants were vernalized at $4^{\circ} \mathrm{C}$ for 3 months, allowed to refoliate, and then tested by ELISA a second time. Results of ELISA on vernalized seedlings were verified by PCR.

Fruit transmission tests. The ability of aphids to transmit PPV from peach fruit was tested by several different methods over two growing seasons. Orchard-collected fruit were obtained from trees identified as PPV-infected with the assistance of R. Welliver and colleagues (Pennsylvania Department of Agriculture, Harrisburg) during statewide surveys associated with the PPV eradication program. Fruit was stored for 1 to 4 weeks at $4^{\circ} \mathrm{C}$ in the biocontainment facility until used. In some cases, fruit was rinsed in $0.5 \%$ sodium hypochlorite (10\% Chlorox), rinsed five times in deionized water, and dried before storage. For all experiments, fruit was rinsed in water and dried immediately before use.

Preliminary tests in 2001 utilized Colmo pea as the bioassay indicator plant. For these tests, aphids were starved for $30 \mathrm{~min}$ and then placed on washed fruit. Aphids ( $\approx 50$ to 100 per fruit) were allowed to settle and begin probing. Each fruit with feeding aphids was placed adjacent to a healthy 7-day-old Colmo pea seedling and caged. Aphids were allowed to move between the peach fruit and pea seedling for $24 \mathrm{~h}$, and then the fruit was removed and the seedling sprayed with insecticide. Peach fruit were collected, washed, and assayed by ELISA to verify PPV infection. Seedlings were observed for 3 weeks for symptom development, then tested by ELISA.

A second type of test in 2001 examined aphid transmission from PPV-infected peach fruit to healthy peach seedlings. For these tests, individual PPV-infected peach fruit with 50 to 100 probing aphids were placed adjacent to a 4- to 6-week-old healthy peach seedling (cv. Lovell) growing in a $15-\mathrm{cm}$-diameter pot, and the pot was placed in a screened box cage for a 3-day inoculation access period. During this time, aphids were free to move between fruit and seedling. The seedling was sprayed, moved to the greenhouse, observed over a 60- to 90-day period for symptoms, and then tested by ELISA for PPV.

In 2002, a third experimental design was used to test for PPV transmission from fruit by different aphid species. In these replicated tests, starved aphids were added to infected peach fruit held in a plastic container and the aphids allowed to settle and initiate probing over a 15 - to $30-\mathrm{min}$ period. Individual peach fruit with the probing aphids then were placed in the top half of plastic cylindrical tube cages approximately $10 \mathrm{~cm}$ in diameter and $36 \mathrm{~cm}$ high. The top of the cage was closed with screen mesh and the fruit was held in the top third of the cage by cork stoppers inserted though the cage just below the fruit. The cage containing fruit and aphids was placed over a single 4- to 6-week-old peach seedling growing in a $15-\mathrm{cm}$-diameter pot. Aphids were free to move from fruit to seedling over a 3-day period and then treated as described above. Following ELISA, these seedlings were vernalized for 3 months at $4^{\circ} \mathrm{C}$ in a coldroom, then returned to the greenhouse and allowed to resume growth. Resulting new foliage was analyzed by PCR to verify chronic systemic PPV infection in trees inoculated from PPV-infected fruit sources.

ELISA. Standard double-antibody sandwich ELISA was performed to verify PPV infections of seedling leaf tissue and peach fruit using the Durviz test system (Agdia, Elkhart, IN) for PPV. For tests of fruit, fruit homogenates in sample buffer were allowed to incubate at $4{ }^{\circ} \mathrm{C}$ for several hours before loading into plates. This incubation allowed inhibitory components to precipitate, resulting in reduced background readings and increased sensitivity. Fruit samples consisted primarily of the outer 1 to $3 \mathrm{~mm}$ of surface tissue.

PCR testing and verification. Total RNA was extracted from $50 \mathrm{mg}$ of fresh or frozen leaf tissue using previously described methods (24) or the RNAqueous small-scale phenol-free total RNA isolation kit (Ambion, Austin, TX) following the manufacturer's protocol. The SuperScript One-Step real-time (RT)PCR with Platinum Taq kit (Invitrogen, Carlsbad, CA) was used throughout as $25-\mu l$ reactions in a Smart Cycler (Cepheid, Sunny- 
vale, CA). PPV-specific primers (CCAATAAAGCCATTGTTGGATC and TGTACGGTTCCATACCTTAAGT) and a probe (ACCGTGTAAAGTCATTGCACCGACTTG) that annealed to a conserved region of the PPV coat protein gene were used to generate PPV-specific cDNA and PCR and RT-PCR products. Probes for RT-PCR (synthesized by Applied Biosystems Inc., Foster City, $\mathrm{CA})$ were labeled at the $5^{\prime}$ end with the fluorescent reporter dye 6-carboxy-flourescin (FAM), and labeled at the $3^{\prime}$ end with the quencher dye 6-carboxy-tetramethyl-rhodamine (TAMRA). The RT-PCR mixture contained $1 \times$ reaction mix $(0.2 \mathrm{mM}$ each dATP, dTTP, dCTP, and dGTP; $\left.1.2 \mathrm{mM} \mathrm{MgSO}_{4}\right)$, an additional $4.8 \mathrm{mM}$ $\mathrm{MgSO}_{4}, 200 \mathrm{nM}$ forward and reverse primers, $100 \mathrm{nM}$ FAMTAMARA probe, and $0.5 \mu \mathrm{l}$ of RT/Platinum Taq Mix per reaction. Thermal cycling conditions were $52^{\circ} \mathrm{C}$ for $15 \mathrm{~min}$ for reverse transcription, $95^{\circ} \mathrm{C}$ for $5 \mathrm{~min}$ for Platinum $\mathrm{Taq}$ activation, and 60 cycles of $95^{\circ} \mathrm{C}$ for $15 \mathrm{~s}$ and $60^{\circ} \mathrm{C}$ for $30 \mathrm{~s}$ for PCR. Between $300 \mathrm{pg}$ and $2 \mu \mathrm{g}$ of total RNA or DNA template was used per assay. PPV-specific primers and probes that anneal to a conserved region of the PPV coat protein gene were used to generate PPV-specific cDNA and PCR product. Fluorescence from the FAM reporter was detected at a wavelength of 505 to $537 \mathrm{~nm}$. The cycle threshold $\left(\mathrm{C}_{\mathrm{t}}\right)$ values for each reaction were calculated automatically by the Smart Cycler detection software by determining the point in time (PCR cycle number) at which the reporter fluorescence exceeds background. The size of the PCR product was checked periodically using electrophoresis.

\section{RESULTS}

Transmission tests for vector competence. Four aphid species, Aphis fabae, A. spiraecola, B. persicae, and M. persicae, endemic to stone-fruit-growing areas of North America, consistently transmitted the PENN-3 isolate of PPV. Two species of cereal grain aphids, Metopolophium dirhodum and $R$. padi, were identified as inefficient occasional vectors. In addition, $T$. citricida, an introduced species currently restricted to Florida, also transmitted PPV. In three replicated pea-to-pea transmission tests using Colmo pea as the PPV source (Table 1), the four aphid species, A. fabae, A. spiraecola, B. persicae, and Myzus persicae, were effective vectors with transmission rates of $65,86,58$, and $83 \%$, respectively, in terms of number of plants infected when fed on by multiple aphids per plant. Although the bird cherry-oat aphid, $R$. padi, was encountered as a migrant during aphid trapping in orchards, this species only rarely transmitted PPV ( $2 \%$ of plants infected). Another aphid common to grasses and small grains, the rose-grass aphid, Metopolophium dirhodum, also transmitted PPV to $2 \%$ of test plants. The brown citrus aphid, T. citricida, was an effective vector of PPV, transmitting to $36 \%$ of plants infested. However, this aphid species is not known to occur in major peach-producing regions of the United States. Six aphid species encountered as migrant species in orchards and common to herbaceous orchard ground cover or adjacent crops did not transmit PPV in any of three replicated tests done in parallel with M. persicae as a positive control. These species occur in orchards primarily as accidental migrants or colonizers of ground cover plants and, except for Macrosiphum euphorbiae (27), are not thought to colonize peach.

The objective of these transmission experiments was simply to determine the ability or inability of aphid species to transmit PPV. These results indicate relative degrees of vector competency among aphid species and the data suggest there may be differences among species in transmission efficiency. However, standardizing virus titer in tissues of acquisition hosts among treatments was impossible and the exact number of aphids feeding on each test plant was highly variable. Therefore, we do not attach statistical significance to that data suggesting differences in transmission efficiency among effective vector species. Difference in percentage of plants infected among treatments is a very indirect measure of vector efficiency, especially when using multiple aphids per test plant and unregulated probing. Current studies are underway to compare aphid species transmission efficiencies using more highly controlled single-aphid tests.

Transmission efficiency of one of the most effective vectors, Myzus persicae, for PPV-PENN-3 was determined in single-aphid tests using timed acquisition probes on PPV-infected pea, followed by transmission to pea. In three tests involving 30 aphids each, transmission efficiency for $M$. persicae averaged $10 \%$ when using individual aphids in observed single-probe tests and one aphid per seedling for the transmission assay.

The four most competent aphid vectors, $M$. persicae, A. spiraecola, A. fabae, and B. persicae, identified in the pea-to-pea tests (Table 1) were selected for additional testing to determine their effectiveness in transmitting PPV from peach to peach, as would occur in natural orchard situations. Aphids were allowed to initiate probing on 3- to 4-month-old PPV-infected peach seedlings showing veinal chlorosis and leaf distortion symptoms of infection. The infected source tree and feeding aphids then were placed in a plexiglass box cage with five to six healthy peach seedlings for a 3-day period. Two to four replicates were done for each treatment in each test. In three tests, all four aphid species consistently transmitted PPV (Table 2). The percentage of plants infected when fed on by viruliferous $M$. persicae, $A$. spiraecola, $A$. fabae, and $B$. persicae, was $63,31,38$, and $32 \%$, respectively. Thus, the peach seedling to peach seedling transmission test results were similar to the results of the pea-to-pea tests. These tests validated the usefulness of the pea tests as a preliminary screening tool and verified the potential importance of these aphid species as PPV vectors in North American orchards.

TABLE 1. Vector competence of 13 North American aphid species to acquire and transmit Plum pox virus (PPV)-PENN-3 ${ }^{\mathrm{a}}$

\begin{tabular}{|c|c|c|c|c|c|}
\hline Aphid species & Test 1 & Test 2 & Test 3 & Total & Percentage $(\%)$ \\
\hline Acyrthosiphon pisum & $0 / 30$ & $0 / 37$ & $0 / 42$ & 0/109 & 0 \\
\hline Aphis fabae & $17 / 20$ & $20 / 40$ & $28 / 40$ & $65 / 100$ & 65 \\
\hline A. glycines & $0 / 20$ & $0 / 20$ & $0 / 13$ & $0 / 53$ & 0 \\
\hline A. spiraecola & $20 / 20$ & $32 / 40$ & $34 / 40$ & $86 / 100$ & 86 \\
\hline Aulacorthum solani & $0 / 40$ & $0 / 44$ & $0 / 48$ & $0 / 132$ & 0 \\
\hline Brachycaudus persicae & $11 / 20$ & $27 / 40$ & $20 / 40$ & $58 / 100$ & 58 \\
\hline Macrosiphum euphorbiae & $0 / 46$ & $0 / 40$ & $0 / 40$ & $0 / 126$ & 0 \\
\hline Metopolophium dirhodum & $0 / 14$ & $0 / 40$ & $2 / 40$ & $2 / 94$ & 2 \\
\hline Myzus persicae & $20 / 20$ & $27 / 40$ & $36 / 40$ & $83 / 100$ & 83 \\
\hline Rhopalosiphum maidis & $0 / 20$ & $0 / 40$ & $0 / 40$ & $0 / 80$ & 0 \\
\hline R. padi & $2 / 23$ & $0 / 40$ & $1 / 128$ & $3 / 191$ & 2 \\
\hline Sitobion avenae & $0 / 20$ & $0 / 41$ & $0 / 39$ & $0 / 80$ & 0 \\
\hline Toxoptera citricida & $7 / 11$ & $4 / 12$ & $12 / 41$ & $23 / 64$ & 36 \\
\hline
\end{tabular}

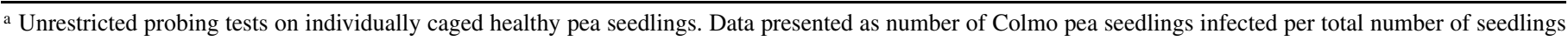
individually infested with 25 to 50 aphids of each species previously acquisition fed for 15 min on PPV-infected Colmo pea. Positive transmissions were verified in all plants by enzyme-linked immunosorbent assays of pea seedlings $\approx 3$ weeks postinoculation. 
Fruit transmission tests. In 2001, experiments were initiated to verify preliminary reports by Labonne et al. (13) that aphids could acquire and transmit PPV from infected stone fruit. Fruit showing obvious symptoms of chlorotic rings and distorted shape were collected from PPV-infected peach trees in Franklin Co., PA. Individual fruit were analyzed by ELISA following their use in transmission tests to verify PPV infection. Of 26 fruit showing PPV symptoms and testing positive, the average ELISA value (absorbance at $405 \mathrm{~nm}$ ) was 0.5 , with a positive threshold set at 0.05 . Absorbance values ranged from 0.1 to 1.12 . These readings suggested that individual fruit contained relatively high titers of virus. In the first set of experiments, $M$. persicae aphids were free to move and probe between infected peach fruit and healthy pea seedlings for $24 \mathrm{~h}$, after which the seedlings were sprayed with insecticide and observed for several weeks. In a series of four similar experiments (Table 3), a total of 7 of 180 infested pea seedlings (4\%) became infected with PPV. This was the first evidence that the Pennsylvania isolates of PPV could be acquired and transmitted by aphids from infected fruit.

Because the rate of transmission from PPV-infected fruit was low when compared with previous results using pea as the bioassay host in pea-to-pea tests, a second, smaller experiment was set up using peach seedlings as the bioassay host. Using the same fruit as in the above pea test, 50 to $100 \mathrm{M}$. persicae aphids were allowed to initiate probing on infected peach fruit. Then, an individual fruit with probing aphids was placed next to a healthy peach seedling and caged for a 3-day inoculation access period. Results of two experiments (Table 3) indicated that four of six infested peach seedlings (67\%) became infected when fed on by viruliferous $M$. persicae. These data (Table 3 ) suggested that aphid transmission from peach fruit to peach seedlings was efficient. Therefore, all subsequent fruit tests utilized only peach fruit to peach seedling transmissions.

In 2002, PPV-infected fruit (PPV-PENN-7) was obtained from ELISA-positive peach trees in York County, PA. These fruit lacked visible symptoms, but tested positive by ELISA following their use in the transmission tests. Fruit were stored at $4{ }^{\circ} \mathrm{C}$ for 2 to 4 weeks before use. Infected peach fruit were used in "hanging peach tests" in which PPV-infected peach fruit infested with 50 to 100 aphids each were suspended above healthy peach seedlings in single plant cages for a 3-day inoculation access period. Four aphid species were compared for ability to transmit PPV from fruit to trees in two independently replicated tests completed approximately 2 weeks apart. The ability of the four aphid species to transmit PPV from fruit (Table 4) was very different from results obtained using peach seedlings as sources (Table 2). Two aphid species, M. persicae and A. spiraecola, transmitted PPV very effectively from fruit, with 50 and $35 \%$ of test tree seedlings, respectively, becoming infected. By comparison, A. fabae and $B$. persicae did not transmit PPV from fruit to any of 40 seedlings tested, even though these aphids were observed to probe and feed on peach fruit in a similar manner to the vector species. In order to determine whether the seedlings became systemically infected, all test seedlings initially were analyzed by ELISA and then vernalized at $4^{\circ} \mathrm{C}$ for 3 months. Trees were returned to the green- house postvernalization, allowed to refoliate, and new foliage tested for PPV by RT-PCR. The original ELISA-positive and -negative trees were confirmed by RT-PCR. Results indicated that aphids found in Pennsylvania are capable of transmitting PPV from fruit to young peach seedlings, and that these PPV infections are persistent through seedling vernalization.

\section{DISCUSSION}

Three North American isolates of PPV, recovered from naturally infected peach trees in three counties of Pennsylvania, were transmitted efficiently from infected peach trees or fruit to healthy peach seedlings by several indigenous aphid species. Results were consistent with observed patterns of PPV spread in the quarantined areas of Adams County, PA, that suggested vector spread among adjacent orchards and downwind of infection foci. In our tests, $M$. persicae, A. fabae, A. spiraecola, and B. persicae consistently transmitted PPV in two types of tests involving peato-pea and peach-to-peach transmission of PPV from infected foliage to healthy seedlings. Three of these species, $M$. persicae, $A$. spiraecola, and B. persicae, are known to be capable of colonizing peach at some point in their lifecycles (27). Surveys of aphid populations in Pennsylvania peach orchards over the past 2 years by G. Krawczyk (Pennsylvania State University-FREC, Biglerville, personal communication) and J. Stimmel (PDA, Harrisburg, personal communication) have indicated that $A$. spiraecola is the most numerous aphid in the orchard aphid population in Adams County, PA. Surveys performed by C. Wallis (Pennsylvania State University, unpublished data) in central Pennsylvania in Centre and Mifflin counties, PA in 2002 and 2003, indicated that A. spiraecola and M. persicae ranked as the second and third most numerous species trapped in peach orchards during the growing season. The most numerous migrant aphid trapped in central Pennsylvania orchards was $R$. maidis, the corn leaf aphid, which is not a vector of PPV. Both A. spiraecola and M. persicae have been observed colonizing peach and apple early in the season on expanding leaves. However, as the leaves mature, the aphids leave the trees and exist in the orchards as migrant species moving from herbaceous hosts. $B$. persicae, which colonizes and survives on peach, has been observed only rarely in aphid surveys in Pennsylvania, and A. fabae is not known to colonize or feed on stone fruit and occurs only transiently as a migrant species. The fifth vector species tested only in pea-to-pea tests, the bird cherryoat aphid, $R$. padi, occurs as a migrant in orchards located adjacent to small grain fields. However, $R$. padi was a very inefficient vector of PPV in our tests and probably not associated with PPV epidemics. The other occasional vector, Metopolophium dirhodum, is observed only rarely on small grains in Pennsylvania. However, this species is very common in some areas of California, a major peach-growing state, where small grains are grown. The brown citrus aphid ( $T$. citricida) proved to be a relatively effective vector in our preliminary pea-to-pea tests. It is interesting to note that T. citricida is an effective vector of PPV, even though this species is not found in Europe, where PPV originated and spread. This species appears to be an effective vector despite the absence of

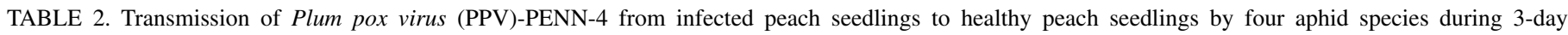
unrestricted probing tests ${ }^{\mathrm{a}}$

\begin{tabular}{|c|c|c|c|c|c|}
\hline Aphid species & Test 1 & Test 2 & Test 3 & Total & Percentage $(\%)$ \\
\hline Myzus persicae & $13 / 15$ & $11 / 24$ & $8 / 12$ & $32 / 51$ & 63 \\
\hline Aphis fabae & $8 / 15$ & $2 / 21$ & $8 / 12$ & $18 / 48$ & 38 \\
\hline A. spiraecola & $3 / 14$ & $8 / 19$ & $3 / 12$ & $14 / 45$ & 31 \\
\hline Brachycaudus persicae & $8 / 15$ & $4 / 23$ & $4 / 12$ & $16 / 50$ & 32 \\
\hline
\end{tabular}

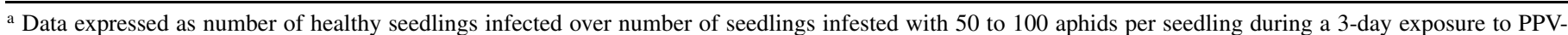
infected and healthy test seedlings. Positive transmissions initially were verified by enzyme-linked immunosorbent assays of each infested peach seedling $\approx 90$ days postinoculation. Systemic infection of seedlings then was verified by real-time polymerase chain reaction following a 90 -day vernalization at $2^{\circ} \mathrm{C}$ and regrowth of foliage. 
previous selection pressure for PPV to adapt to T. citricida as a vector. At this time, T. citricida only occurs in the United States in the state of Florida and is not a threat as a PPV vector in the major stone-fruit-growing states. Of 12 aphid species we identified as migrant species invading peach orchards, 6 did not transmit PPV in three replicated tests (Table 1). Caution must be used in interpreting our report of nonvector species, because these tests used only one population of each aphid species and one PPV isolate (PENN-3) for preliminary screening for vector competence. Although our preliminary screening for vector competence utilized Colmo pea for the PPV source host and the indicator plant, we believe this had little impact on the ability of PPV to be transmitted. All aphid species were found to settle and probe more readily on pea than on peach; and pea-adapted PPV isolates were efficiently transmitted from pea back to peach by several aphid species. PPV adaptation to pea did not eliminate the ability for aphid transmission or for the isolate to infect peach. Current studies in our lab (unpublished data) indicate that very few mutations differentiate pea-adapted and peach-adapted PPV isolates when maintained by serial aphid transmissions, and none of these mutations are associated with coat protein or helper component genes. Evidence does indicate, however, that biotypes within an aphid species may differ in their ability to vector PPV. Although Hyalopterus pruni is an important PPV vector in eastern Europe $(9,32)$, a population of $H$. pruni in France was unable to transmit PPV in replicated tests using three different PPV isolates (13). In addition, one French clone of $A$. gossypii was an efficient vector, while a second clone of $A$. gossypii did not transmit the same PPV isolate in four tests $(13,17)$. Therefore, more thorough testing is required to verify nonvector species and to identify variations among aphid biotypes for PPV transmission. It is likely that occasional transmissions of PPV by "nonvector" species might be detected with more intense laboratory testing.

The ability of Pennsylvania populations of aphids to transmit PPV-D-like isolates from infected peach fruit to healthy peach seedlings independently verified the work of Labonne et al. (12) demonstrating transmission of PPV-M isolates from southeastern France from infected peach fruit to peach seedlings. Using PPVM-infected fruit as virus sources and Myzus persicae as vectors, Labonne and coworkers obtained infection rates of $86 \%$ from apricot fruit and 0 to $11 \%$ from peach. Transmission effectiveness of PPV-M varied with peach cultivar, and aphids were able to transmit PPV-M from fruit at all stages of maturity regardless of symptom expression.

In our preliminary tests for PPV-D transmission from infected peach fruit using the PENN-4 isolate, $M$. persicae as vector, and Colmo pea as the indicator species, we obtained only $4 \%$ transmission. However, when peach GF-305 seedlings were used as indicator plants in parallel tests, aphids transmitted to $67 \%$ of test seedlings. In these experiments, all fruit used as PPV sources displayed distortion and chlorotic ringspot symptoms and were

TABLE 3. Aphid acquisition of Plum pox virus (PPV)-PENN-4 from peach fruit and transmission to Colmo pea or GF-305 peach seedlings ${ }^{\mathrm{a}}$

\begin{tabular}{llcc}
\hline & & \multicolumn{2}{c}{ Bioassay host plant } \\
\cline { 3 - 4 } Test no. & Vector species & Colmo pea & GF-305 peach \\
\hline 1 & Myzus persicae & $1 / 30$ & nd \\
2 & M. persicae & $1 / 30$ & nd \\
3 & M. persicae & $3 / 30$ & $2 / 3$ \\
4 & M. persicae & $2 / 60$ & $2 / 3$ \\
Totals & .. & $7 / 180$ & $4 / 6$
\end{tabular}

${ }^{\text {a }}$ Data presented as the number of seedlings infected per number seedlings infested with 50 to 100 aphids per seedling following simultaneous exposure to infected peaches and healthy test seedlings over a 48-h combined acquisition and inoculation access period; nd = not done. Positive transmissions were verified by enzyme-linked immunosorbent assays of each infested peach seedling at 3 weeks (pea) or 3 months (peach) postinoculation.
ELISA positive for PPV. These results indicated less-efficient PPV infection of pea when transmitted from peach fruit to pea seedlings. Reduced pea infections suggested that PPV was transmitted less efficiently by aphids from peach to pea, or that the PPV isolate in peach was not well adapted to infecting and replicating in pea. Because pea-to-pea transmission rates by four aphid species were relatively high (58 to $83 \%$ ), aphid probing behavior and vector efficiency on pea did not seem to be an inhibitory factor to infection once the isolate was adapted to replicating in pea. These results suggest that the initial interspecies movement of PPV between plant hosts might result in decreased infection or replication efficiency and may explain the low infection rates observed when peach-adapted PPV was first transmitted from peach to pea hosts. In our experience, transmission efficiency tests were consistent when using the same plant species for virus source and as indicator. Therefore, only peach fruit to peach seedling transmissions were done in subsequent tests. For two replicated tests done using fruit collected in 2002, peach fruit were harvested from trees infected with the PENN-7 isolate of PPV and stored at $4^{\circ} \mathrm{C}$ for 2 and 4 weeks before testing. Although the fruit were symptomless, ELISA tests verified high virus titer in outer layers of the fruit. Two vector species, $M$. persicae and A. spiraecola, transmitted PPV to peach seedlings from 50 and $35 \%$ of the fruit, respectively. Surprisingly, A. fabae and B. persicae did not transmit PPV from fruit, even though they did transmit PPV from leaves. When observed microscopically, all four aphid species were seen to readily initiate probing and feeding on peach fruit within $5 \mathrm{~min}$ of being placed on fruit. In addition, replicated survival studies on peach fruit (data not shown) indicated that all four aphid species could survive on caged peach fruit for a minimum of 3 days. Therefore, behavioral differences during probing associated with virus acquisition were not obvious; and aphid survival and reproduction on fruit for at least 3 days suggested that aphids did have the opportunity to acquire virus. Further studies are needed to ascertain the mechanisms responsible for this observed difference among aphid species for ability to transmit PPV from fruit.

The range of aphid species capable of transmitting PPV in eastern North America and important as vectors in the orchard is similar to that reported for western Europe (13), and less similar to that described for eastern Europe $(9,32)$. The most efficient vector on peach in our study was $M$. persicae. The second most efficient vector, A. spiraecola, occurred in the orchard in much higher population numbers over a longer period of time, and for this reason may be the most likely vector associated with PPV spread. Although A. fabae and B. persicae were identified as effective PPV vectors of North American PPV isolates, these species do not make up a significant proportion of the aphid population in orchards. However, it is possible that these less-prevalent vector species could be responsible for PPV movement to reservoir hosts outside the orchard and play an important role in PPV survival

TABLE 4. Transmission of Plum pox virus (PPV)-PENN-7 from infected peach fruit to healthy peach seedlings by four aphid species during 3-day unrestricted probing tests ${ }^{\mathrm{a}}$

\begin{tabular}{lccrc}
\hline Aphid species & Test 1 & Test 2 & Total & Percentage (\%) \\
\hline Myzus persicae & $5 / 10$ & $5 / 10$ & $10 / 20$ & 50 \\
Aphis fabae & $0 / 10$ & $0 / 10$ & $0 / 20$ & 0 \\
A. spiraecola & $5 / 10$ & $2 / 10$ & $7 / 10$ & 35 \\
Brachycaudus persicae & $0 / 10$ & $0 / 10$ & $0 / 20$ & 0 \\
\hline
\end{tabular}

a Data expressed as number of healthy seedlings infected over number of seedlings infested with 50 to 100 aphids per seedling during a 3-day exposure to PPV-infected fruit collected from PPV-infected trees in York County, $\mathrm{PA}$ in 2002. Positive transmissions initially were verified by enzyme-linked immunosorbent assays of each infested peach seedling $\approx 90$ days postinoculation. Systemic infection of seedlings then was verified by real-time polymerase chain reaction following a 90-day vernalization at $2^{\circ} \mathrm{C}$ and regrowth of foliage. 
and epidemiology. The important role of noncolonizing migrant aphids in transmission of other potyviruses has been described (28). Fortunately, PPV surveys conducted by J. Halbrendt (FREC, Biglerville, PA) over the past 2 years have not detected PPV infecting any reservoir hosts in Pennsylvania (personal communication). In eastern Europe, B. helichysi, H. pruni, and Phorodon humuli are important PPV vectors associated with virus spread $(9,32)$. Although all three species occur in North America and use Prunus spp. as primary overwintering hosts $(1,27)$ these species were not identified as major components of aphid populations surveyed in central and southeastern Pennsylvania. Our list of nonvector species is in agreement with those reported by Labonne et al. (13). Because of the rapidly implemented PPV eradication program in Pennsylvania requiring immediate removal of PPVinfected trees, field studies of PPV spread and associations with native aphid populations and flight activity are not possible.

The ability of $M$. persicae and $A$. spiraecola to acquire and transmit PPV from infected peach fruit suggests another mode of PPV movement, allowing the virus to bypass natural barriers and invade new geographical locations. Symptomless infected fruit could be shipped unknowingly to PPV-free areas for fresh market sale, repacking, or canning. Unsold or damaged fruit frequently is discarded to outdoor cull piles and allowed to rot. Our report supports an earlier observation (12) that aphids will land and probe on fruit, and are able to transmit PPV from fruit to seedlings under greenhouse conditions. In Pennsylvania, detection of isolated PPV-infected peach trees located several kilometers from the nearest known PPV-infected orchards provided anecdotal evidence supporting the hypothesis that aphids might occasionally transmit PPV from infected fruit to nearby volunteer Prunus seedlings or to adjacent orchard trees. In several cases, these isolated infected trees were located adjacent to commercial or homeowner cull piles. This potential source of virus can be eliminated easily by burial or destruction of freshly discarded fruit. Seed transmission from infected fruit has not been verified $(20,29)$. The potential mechanical inoculation of a germinating seedling by the infected seed coat is a remote possibility, but would be a rare event. Therefore, volunteer seedlings originating from buried infected fruit are not likely to function as initial virus sources. Additional studies of PPV spread from PPV-infected fruit to healthy trees are needed in order to further assess and verify the risk associated with movement of PPV-infected stone fruit. However, rapid eradication of PPV-infected fruit trees prior to fruit set in the quarantine zone and the inability to maintain fruit development under quarantined greenhouse conditions inhibits additional testing of fruit as PPV sources.

\section{ACKNOWLEDGMENTS}

This project was supported by a grant from the Pennsylvania Department of Agriculture (grant ME 400496) and by USDA-ARS/ APHIS Cooperative Agreement 58-1920-1-103. We thank W. Sackett and D. Sherman for technical assistance.

\section{LITERATURE CITED}

1. Blackman, R. L., and Eastop, V. F. 2000. Aphids on the Worlds Crops. John Wiley \& Sons, Sussex, UK.

2. Bousalem, M., Candresse, T., Quiot-Douine, L., and Quiot, J. B. 1994. Comparison of three methods for assessing Plum pox virus variability: Further evidence for the existence of two major groups of isolates. J. Phytopathol. 142:163-172.

3. Candresse, T., Cambra, M., Dallot, S., Lanneau, M., Asensio, M., Gorris, M. T., Revers, F., Macquaire, G., Olmos, A., Boscia, D., Quiot, J. B., and Dunez, J. 1998. Comparison of monoclonal antibodies and polymerase chain reaction assays for the typing of isolates belonging to the $\mathrm{D}$ and $\mathrm{M}$ serotypes of Plum pox virus. Phytopathology 88:198-204.

4. Candresse, T., MacQuaire, G., Lanneau, M., Bousalem, M., QuitoDouine, L., Quiot, J. B., and Dunez, J. 1995. Analysis of Plum pox virus variability and development of strain-specific PCR assays. Acta Hortic. 386:375-369.

5. Dallot, S., Labonne, G., Boeglin, M., Quiot-Douine, L., Quiot, J. B., and Candresse, T. 1998. Peculiar plum pox potyvirus D-populations are epidemic in peach trees. Acta Hortic. 472:355-365.

6. Damsteegt, V., Stone, A. L., Luster, D. G., Gildow, F. E., Levy, L., and Welliver, R. 2001. Preliminary characterization of a North American isolate of Plum pox virus from naturally infected peach and plum orchards in Pennsylvania, USA. Acta Hortic. 550:145-152.

7. Damsteegt, V., Waterworth, H. E., Mink, G. I., Howell, W. E., and Levy, L. 1997. Prunus tomentosa as a diagnostic host for detection of Plum pox virus and other Prunus viruses. Plant Dis. 81:329-332.

8. Harris, K. 1977. An ingestion-egestion hypothesis of noncirculative virus transmission by aphids. Pages 165-220 in: Aphids as Virus Vectors. K. Maramorosch, ed. Academic Press, New York.

9. Isac, M., Preda, S., and Marcu, M. 1998. Aphid species-Vectors of Plum pox virus. Acta Virol. 42:233-234.

10. Kerlan, C., and Dunez, J. 1979. Differentiation biologique et serologique de souches du virus de la Sharka. Ann. Phytopathol. 11:242-250.

11. Labonne, G., and Lauriaut, F. 1991. Evaluation du numbre de pucerons qui atterrissent sur un arbre en relation avec al dissemination du Plum pox virus. Phytopathol. Mediterr. 30:167-172.

12. Labonne, G., and Quiot, J. B. 2001. Aphids can acquire Plum pox virus from infected fruits. Acta Hortic. 550:79-82.

13. Labonne, G., Yvon, M., Quiot, J. B., Avinert, L., and Llacer, G. 1995. Aphids as potential vectors of Plum pox virus: Comparison of methods of testing and epidemiological consequences. Acta Hortic. 386:207-217.

14. Levy, L., Damsteegt, V., and Welliver, R. 2000. First report of Plum pox virus (Sharka disease) in Prunus persica in the United States. Plant Dis. 84:202.

15. Llacer, G., Avinent, L., and Hermoso de Mendoza, A. 1992. Epidemiology of plum pox (Sharka) virus in Valencia (Spain). Acta Hortic. 309:129-134.

16. Llacer, G., and Cambra, M. 1998. Thirteen years of Sharka disease in Valencia, Spain. Acta Hortic. 472:379-384.

17. Lupoli, R., Labonne, G., and Yvon, M. 1992. Variability in the transmission efficiency of potyviruses by different clones of Aphis gossypii. Entomol. Exp. Appl. 5:291-300.

18. Mazyad, H. M., Nakhla, M. K., Abo-Elela, A., and El-Hammady, M. H. 1992. Occurrence of plum pox (sharka) virus on stone fruit trees in Egypt. Acta Hortic. 309:119-124.

19. Morvan, G. 1988. The epidemiology of Plum pox virus in the apricot orchards of southern France: Description of computer tools and main observations. Acta Hortic. 235:263-270.

20. Myrta, A., Di Terlizzi, B., and Savino, V. 1998. Study on the transmission of plum pox potyvirus through seeds. Phytopathol. Mediterr. 37:41-44.

21. Nemchinov, L., and Hadidi, A. 1996. Characterization of the sour cherry strain of Plum pox virus. Phytopathology 86:575-580.

22. Nemeth, M. 1994. History and importance of plum pox in stone-fruit production. Eur. Plant Prot. Organ. (EPPO) Bull. 24:525-536.

23. Reyes, F., Fiore, N., Reyes, M. A., Sepulveda, P., Paredes, V., and Prieto, H. 2003. Biological behavior and partial molecular characterization of six Chilean isolates of Plum pox virus. Plant Dis. 87:15-20.

24. Roossinck, M. J., Kaplan, I., and Palukaitis, P. 1997. Support of a cucumber mosaic virus satellite RNA maps to a single amino acid proximal to the helicase domain of the helper virus. J. Virol. 71:608-612.

25. Rosales, M., Hinrichsen, P., and Herrera, G. 1998. Molecular characterization of Plum pox virus isolated from apricots, plums, and peaches in Chile. Acta Hortic. 472:401-405.

26. Roy, S., and Smith, I. M. 1994. Plum pox situation in Europe. Eur. Plant Prot. Organ. (EPPO) Bull. 24:515-523.

27. Stoetzel, M., and Miller, G. L. 1998. Aphids (Homoptera: Aphididae) colonizing peach in the United States or with potential for introduction. Fla. Entomol. 81:325-345.

28. Summers, C. G., Newton, A. S., Jr., Kirk, M., and Temple, S. R. 1990. Transmission of beet yellows and beet mosaic viruses by noncolonizing aphid vectors. J. Econ. Entomol. 83:2448-2451.

29. Thomidis, T., and Karajiannis, I. 2003. Using ELISA and PCR to test the potential for spread of Plum pox virus by seeds of different stone fruit cultivars. N. Z. J. Crop Sci. 31:69-72.

30. Travis, J. W. 2001. Plum pox virus and other diseases of stone fruits: A field guide. Pennsylvania State University College of Agricultural Sciences, University Park.

31. Wetzel, T., Candresse, T., Ravelonandro, M., Delbos, R. P., Mazyad, H., Aboul-Ata, A. E., and Dune, J. 1991. Nucleotide sequence of the 3'terminal region of the RNA of the El Amar strain of plum pox potyvirus. J. Gen. Virol. 72:1741-1746.

32. Zsuzsa, B., Dalma, P., and Richard, G. 1997. Flight and transmission activity of PPV vector aphids. J. Aphidol. 11:21-27. 